\title{
Tumor neuroendocrino vesical de célula pequeña: a propósito de un caso y revisión bibliográfica
}

\author{
Lahoz Tornos $\mathrm{A}^{*}$, Marrón Penón $\mathrm{M}^{\mathrm{a}} \mathrm{C}^{* *}$, Pardo López $\mathrm{M}^{\mathrm{a}} \mathrm{L}^{* * *}$, Nogueras Gimeno MA**, \\ Pujol Obis $E^{* * * *}$, Del Villar Sordo V*. \\ *Servicio de Medicina Interna, ${ }^{* *}$ Servicio de Urología, ${ }^{* * *}$ Servicio de Anatomía Patológica. \\ ****Servicio de Oncología. Hospital Santa Bárbara. Soria.
}

Actas Urol Esp. 2006;30(8):835-838

\section{RESUMEN}

TUMOR NEUROENDOCRINO VESICAL DE CÉLULA PEQUEÑA: A PROPÓSITO DE UN CASO Y REVISIÓN BIBLIOGRÁFICA

Introducción y objetivos: El tumor neuroendocrino de célula pequeña es una neoplasia infrecuente, siendo el estudio inmunohistoquímico clave en el diagnóstico. Aportamos un nuevo caso, hacemos referencia al plan de tratamiento y evolución en los primeros meses tras el mismo.

Material y métodos: Se describe la clínica, diagnóstico y tratamiento de este tumor. Revisión bibliográfica.

Conclusiones: El tumor neuroendocrino de célula pequeña es una neoplasia infrecuente, en la que el estudio inmunohistoquímico es clave en el diagnóstico. El diagnóstico diferencial incluye el carcinoma de células transicionales de alto grado y el linfoma primario y secundario. El tratamiento estándar se basa en quimioterapia más cirugía.

Palabras clave: Tumor de célula transicional. Tumor neuroendocrino de célula pequeña.

\section{ABSTRACT}

\section{SMALL CELL NEUROENDOCRINE TUMOUR OF THE BLADDER: WITH REFERENCE TO A CASE AND BIBLIOGRAPHICAL REVISION}

Introduction and objectives: The small cell neuroendocrine tumour is an infrecuent neoplasia, with inmunohistochemistry being the key to diagnosis. We present a new case making reference to treatment and its evolution there after.

Material and methods: The clinic, diagnosis and treatment of this tumour is described. Bibliographical revision follours.

Conclusions: The neuroendocrine tumour of small cell is an infrecuent neoplasia, in which the inmunohistochemistry study is key in the diagnosis. The differential diagnosis includes the high degree diferentiation transitionals cells carcinoma and primary and secondary linfoma. The standard treatment is based on chemotherapy plus surgery.

Keywords: Transitional cell tumour. Small cell neuroendocrine tumour.

$\mathrm{E}$ carcinoma de célula pequeña (CCP) de origen extrapulmonar puede originarse de forma primitiva en distintos órganos: piel, mama, cavidad nasal y senos paranasales, laringe, tráquea, timo, glándulas salivares, parótidas, tracto gastrointestinal, útero, cérvix, riñón, uréteres, vejiga y próstata. El carcinoma neuroendocrino de célula pequeña vesical, es una tumoración infrecuente.
La localización vesical primaria del carcinoma de células pequeñas, supone alrededor del 0,5\% del total de tumores vesicales. Este tumor, predomina fuertemente en el varón y ocurre entre la $5^{\underline{a}}$ y $9^{a}$ décadas de la vida. Sus síntomas de presentación son la hematuria, con o sin disuria. Se discute el origen de las células pequeñas, existiendo tres teorías que intentan explicarlo: origen en células 
madre, en el sistema neuroendocrino APUD incluido en el epitelio de transición o bien aunque menos probable, a partir de metaplasia de células de mucosa urotelial. Los tumores neuroendocrinos pueden ser puros o combinados. Aportamos un nuevo caso y hacemos referencia al plan de tratamiento y evolución en los primeros meses tras el tratamiento.

\section{CASO CLÍNICO}

Varón de 78 años, que presenta cuadro de hematuria macroscópica monosintomática. Entre sus antecedentes destacan HTA y adenocarcinoma de próstata (T3, NO, MO) en tratamiento con bloqueo hormonal completo. El paciente fue estudiado inicialmente por el servicio de urología de otro centro hospitalario. Se realizaron distintos estudios analíticos y de imagen. En mayo de 2004, se realizó resección transuretral vesical (RTU) de varias tumoraciones de aspecto papilar sobre cara lateral izquierda. El diagnóstico anatomopatológico fue carcinoma de células transicionales grado III, realizándose quimioprofilaxis intravesical con mitomicina. Tres meses más tarde, el paciente acudió al servicio de urgencias de nuestro hospital, por presentar cuadro de hematuria franca, con coágulos, de 18 horas de evolución, destacando en la analítica una leve anemia. Las radiografias de tórax y abdomen no mostraban hallazgos significativos. Se realizó una urografía intravenosa, donde se objetivó un defecto de repleción y rigidez de pared izquierda de vejiga, lo que sugería una infiltración tumoral (Fig. 1). El paciente fue dado de alta, tras una evolución favorable de la hematuria con lavados vesicales, a la espera de nueva RTU, acudiendo antes de la cita prevista, por presentar nuevamente hematuria. En octubre de 2004, se realiza la RTU, evidenciándose lesiones incrustantes en cúpula y cara lateral izquierda de vejiga. La lesión en cúpula era nodular, siendo papilar la de cara lateral, a su vez existían lesiones papulosas, amarillentas en toda la vejiga. El estudio de extensión mediante TAC toracoabdómino-pélvico, mostró una mínima irregularidad lateral izquierda vesical. El estudio anatomopatológico, fue compatible con tumor neuroendocrino de célula pequeña. Microscópicamente se apreciaba una población monomorfa de cé-

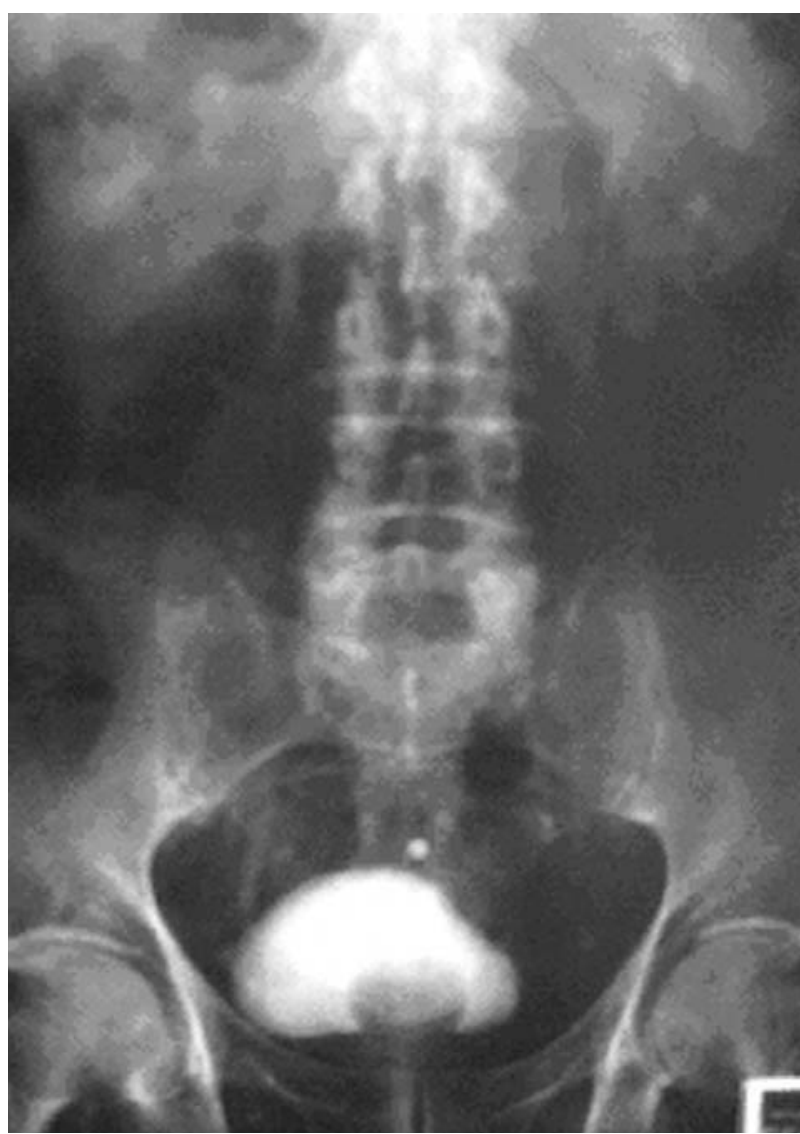

FIGURA 1. Urografía intravenosa a los 25 min; se visualizan varios defectos de repleción en vejiga.

lulas pequeñas y redondas (Fig. 2) con núcleos hipercromáticos, sin nucleolo evidente, con numerosas figuras de mitosis. Dichas lesiones, crecían de forma difusa, infiltrando el tejido conjuntivo subepitelial, respetando la muscular propia. Presentaba además, extensas áreas de necrosis tumoral, sin observarse claras imágenes de permeaciones vasculares. La inmunohistoquímica, demostró positividad para citoqueratinas (AE1/AE3), cromogranina (Fig. 3) y enolasa y negatividad para antígeno común leucocitario (LCA), CK7, CK20, CAM 5.2. Un mes y medio más tarde, el servicio de oncología de nuestro hospital inicia tratamiento con quimioterapia, combinando cisplatino con etopóxido. Al finalizar tres ciclos de tratamiento, se realiza nueva exploración endovesical, con biopsias múltiples, no observándose recidiva tumoral, siendo el examen microscópico negativo para malignidad. El paciente está asintomático y sigue revisiones programadas. 


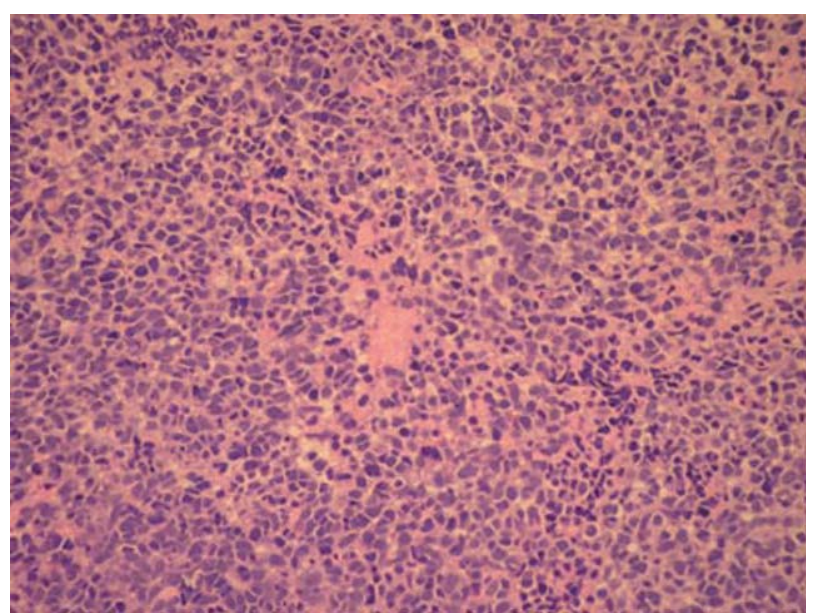

FIGURA 2. Las células neoplásicas son pequeñas y redondas.

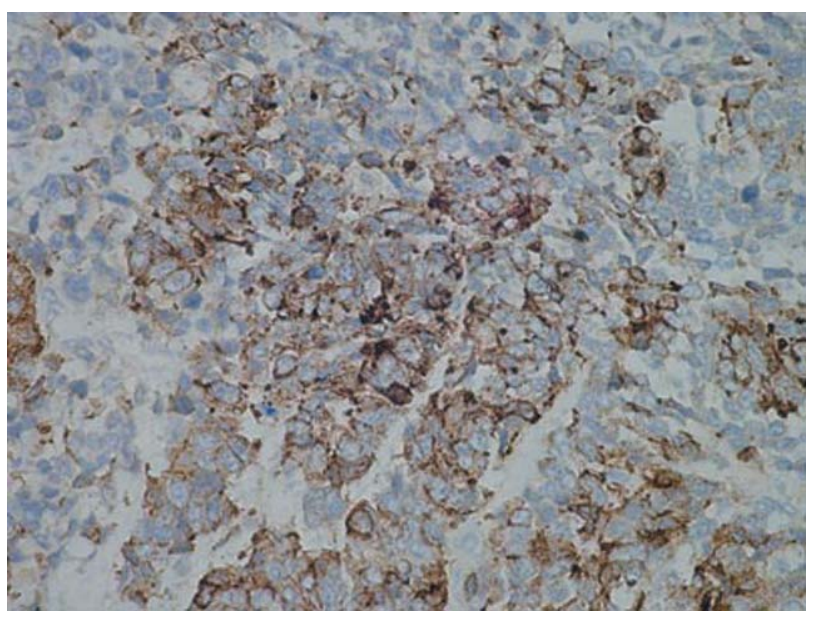

FIGURA 3. Inmunohistoquimica. Los marcadores neuroendocrinos son positivos en las células neoplásicas. Cromogranina.

\section{DISCUSIÓN}

Un 20\% del total de carcinomas de células pequeñas (oat-cell) extrapulmonares primarios, se localizan en la vejiga urinaria, suponiendo un 0,5\% del total de tumores vesicales ${ }^{1}$. Clínicamente, el síntoma predominante es la hematuria $(90 \%)^{2}$, que puede ser micro o macroscópica, a la que puede asociarse disuria y polaquiuria.

La histología, inmunohistoquímica y estructura de estos tumores, son indistinguibles del carcinoma de célula pequeña del pulmón y otras localizaciones epiteliales. Para confirmar su origen extrapulmonar debe realizarse un TAC torácico. El carcinoma de célula pequeña de vejiga está asociado en un $50 \%$ de los casos a otro tumor epitelial (carcinoma de célula transicional, adenocarcinoma, carcinosarcoma - 10 casos descritos-, carcinoma escamoso o tumor carcinoide) ${ }^{3}$, lo cual, se apoyaría en la teoría de histogénesis acerca del inicio de los carcinomas neuroendocrinos en una célula totipotencial. El aspecto habitual de estas tumoraciones, es de masas fungosas o polipoideas, con gran componente vascular y áreas ulceronecróticas ${ }^{1}$ responsables de las hematurias que presentan los pacientes en estadios avanzados. Su tamaño suele ser de 4 a $10 \mathrm{~cm}$. Las paredes vesicales laterales y la bóveda, son las localizaciones más frecuentes, en el $4,7 \%$ de las ocasiones aparecen sobre un divertículo. Histológicamente, infiltra ocasionalmente el tejido fibroadiposo perivesical, cuando esto ocurre, existen metástasis en un $87 \%$ de los casos. Las células neoplásicas varían de células pequeñas, a células de tipo intermedio, algunos autores proponen la subdivisión: CCP tipo "oat-cell" y CCP célula de tipo intermedio. Desde el punto de vista inmunohistoquímico, presentan un alto porcentaje de positividad a marcadores neuroendocrinos tales como la enolasa (se expresa en el $87 \%$ de los casos) y sinaptofisina, también se ha demostrado positividad para citoqueratinas, y ocasionalmente cromogranina (se expresa en $1 / 3$ de los casos), LEU-7, bombesina. Cuando el tumor presenta una atipia marcada, no expresa ninguno de estos marcadores o carece de gránulos neurosecretores. Es importante diferenciar los tumores sólidos de célula pequeña, de los tumores con diferenciación neuroendocrina focal. Estos últimos, tienen estructuras glandulares con células neuroendocrinas aisladas, sin embargo, no existe ninguna diferenciación neuroendocrina difusa. El tumor puro neuroendocrino, se caracteriza por la expresión difusa de los marcadores neuroendocrinos en el 50-100\% de las células ${ }^{4}$. En algunos casos se observan carcinomas neuroendocrinos con expresión débil de cromogranina A y expresión muy fuerte de SNP y viceversa.

El diagnóstico diferencial del carcinoma neuroendocrino vesical, implica el carcinoma de célula pequeña metastásico de otros lugares, tumor de célula transicional de alto grado, carcinoma plasmocitoide, el linfoma primario (con menor actividad proliferativa que el tumor neuroendocrino) o secundario de vejiga. Puede plantear- 
se una dificultad diagnóstica en el tumor de célula pequeña primario de próstata que vierta células a la orina, en este caso, sería de gran ayuda un examen por cistoscopia negativo con mucosa normal. En nuestro caso, puede tratarse de un error diagnóstico inicial, dada la dificultad descrita en el diagnóstico diferencial con el carcinoma de célula transicional de alto grado ${ }^{1} \mathrm{o}$ bien corresponder a la toma de biopsias en dos áreas distintas dentro de la misma tumoración, lo cual también está descrito en la literatura, existiendo componentes entremezclados o bien áreas delimitadas dentro de la lesión. Los tumores neuroendocrinos, son tumores que suelen descubrirse en estadios avanzados con amplia afectación vascular y linfática, con rápido crecimiento y mala respuesta a los tratamientos aplicados. Se ha sugerido que el estadio clínico no está asociado independientemente a la supervivencia $^{5}$. Otros autores, sin embargo, consideran como factores de mal pronóstico: edad > 65 años, alto estadio TNM y enfermedad metastásica como forma de presentación.

La incidencia metastásica precoz supone un $56 \%$ de los casos. La tasa de mortalidad es muy alta, 3 veces superior al tumor no neuroendocrino, llegando al 68,7\% antes de los 2 años tras el diagnóstico. En su evolución se comporta como el CCP pulmonar, siendo peor en comparación con carcinomas uroteliales de alto grado. El pronóstico mejora en aquellos pacientes tratados con quimioterapia basada en cisplatino. La supervivencia media suele ser de 9 a 13 meses $^{6}$. La supervivencia a los 5 años para los pacientes con enfermedad local es del 8\%. Las localizaciones más comunes para la extensión de la enfermedad, incluyen: ganglios linfáticos regionales $56 \%$, óseas $44 \%$, hígado $33 \%$ y pulmón $20 \%$. El tumor de célula pequeña presenta con frecuencia diferenciación neuroendocrina y en ocasiones es posible la secreción de hormonas, dando lugar a síndromes paraneoplásicos de tipo metabólico (hipercalcemia), endocrino (secreción de $\mathrm{ADH}$ ) o de tipo neurológico (fenómenos de autoinmunidad como: síndromes miasteniformes). El tratamiento estándar se basa en quimioterapia más cirugia ${ }^{7,8}$ (cistectomía parcial, radical o resección transuretral). No hay datos estadísticamente significativos favorables a un determinado tipo de tratamiento local, incluyendo el tratamiento con radioterapia.
La cistectomía parcial está indicada en los casos de tumores menores de $5 \mathrm{~cm}$, no infiltrantes, únicos o múltiples, cuando no es posible realizar cistectomía radical, en combinación con quimioterapia. En nuestro caso, donde existían lesiones múltiples no infiltrantes acompañadas de un adenocarcinoma prostático no organoconfinado, se optó por quimioterapia sistémica asociada a RTUs iterativas. No se han descrito en la literatura casos similares al nuestro. La cistectomía radical combinada con quimioterapia se aplicaría cuando no es posible la conservación del órgano y no existe enfermedad diseminada.

$\mathrm{El}$ régimen de quimioterapia varía según el tumor sea de componente único (cisplatino y etopóxido) o de componente mixto (metotrexate, vinblastina, doxurrubicina y cisplatino). En algunos centros, se ha intentado el tratamiento con cirugía más radioterapia con o sin quimioterapia, observándose un peor control de la recidiva tardía y mayor irregularidad de las supervivencias respecto al tratamiento con cirugía y QT. No se ha demostrado ninguna diferencia en la supervivencia, entre los tumores puros y los tumores histológicos mixtos.

\section{REFERENCIAS}

1. Ali SZ, Ruter VE, Zokowski MF. Small cell neuroendocrine carcinoma of the urinary bladder. Cancer. 1997;79(2):356-361.

2. Grignon DJ, Ro JY, Ayala AG, Shum DT, Ordonez NG, Logothetis CJ, et al. Small cell carcinoma of the urinary bladder. Cancer.1992;69(2): 527-536.

3. García Víctor F, Lapuerta Torres E, Moreno Pérez F, Calatrava Gadea S, Díaz Calleja E. Carcinoma vesical de células pequeñas: aportación de un caso. Arch Esp Urol. 2000;53 (1):67-70.

4. Burkhap Helpap. Morphology and therapeutic strategies for Neuroendocrine Tumors of the Genitourinary Tract. Cancer. 2002;95 (2): 1415-1420.

5. Mackey JR, Au HJ, Hugh J, Venner P. Genitourinary small cell carcinoma: determination of clinical and therapeuthic factors associated with survival. J Urol. 1998;159(5):1624-1629.

6. Cuesta Alcala JA, Ripa Saldias L, Aldave Villanueva J, Pascual Piedrola I, Solchaga Martínez A, Ponz González M, et al. Neuroendocrine small cell carcinoma of the bladder. Review of the literature and report of a case. Arch Esp Urol. 2002;55(4):452-456.

7. Siefker-Radtke AO, Dinney CP, Abrahams NA, Moran C, Shen Y, Pisters LL, et al. Evidence supporting preoperative chemotherapy for small cell carcinoma of the bladder: a retrospective review of the M.D Anderson cancer experience. The Journal of Urology. 2004;172(2): 481-484.

8. Dalpiaz O, Al Rabi N, Galfano A, Martignoni G, Ficarra V, Artibani W. Small cell carcinoma of the bladder: a case report and a literature review. Arch Esp Urol. 2003;56(2): 197-202.

Dr. A. Lahoz Tornos

E-mail: lahoztornos@yahoo.es

(Trabajo recibido el 8 de septiembre 2005) 